\title{
Mapping Contaminants Associated with Autism: A Public Health Pilot in New Jersey
}

\author{
Erin Speiser Ihde', Themba Nyirenda' ${ }^{2}$, Aridaman K. Jain ${ }^{3}$, Ji Meng Loh ${ }^{3}$, \\ Francisco Artigas ${ }^{4}$, Christine Hobble ${ }^{4}$, Dom Elefante ${ }^{4}$, Saleh Kojak ${ }^{4}$, \\ Jin Young Shin ${ }^{4}$, Lawrence Rosen ${ }^{1}$ \\ ${ }^{1}$ The Deirdre Imus Environmental Health Center, Hackensack University Medical Center, Hackensack, USA \\ ${ }^{2}$ Department of Research, David \& Alice Jurist Institute for Research, Hackensack University Medical Center, \\ Hackensack, USA \\ ${ }^{3}$ Department of Mathematical Sciences, NJ Institute of Technology, Newark, USA \\ ${ }^{4}$ Meadowlands Environmental Research Institute, New Jersey Meadowlands Commission, Lyndhurst, USA \\ Email: eihde@HackensackUMC.org, Idrdoc@gmail.com, tnyirenda@HackensackUMC.org, \\ AriJain@hotmail.com, loh@njit.edu, Francisco.Artigas@njmeadowlands.gov, \\ Christine.Hobble@njmeadowlands.gov, Dominador.Elefante@nimeadowlands.gov, \\ Sal.Kojak@njmeadowlands.gov, JinYoung.Shin@njmeadowlands.gov
}

Received 12 September 2014; revised 12 October 2014; accepted 8 November 2014

Copyright (C) 2014 by authors and Scientific Research Publishing Inc.

This work is licensed under the Creative Commons Attribution International License (CC BY).

http://creativecommons.org/licenses/by/4.0/

c) (i) Open Access

\section{Abstract}

The rise in reported prevalence rates of autism spectrum disorders (ASDs) is a national concern that continues to grow at a record pace. New Jersey has the highest prevalence rate of autism spectrum disorders (ASDs) among states surveyed, with approximately 1 in 45 children diagnosed. The pilot study focused on toxins potentially linked to autism: arsenic, lead, manganese, mercury, organophosphate pesticides, polychlorinated biphenyls, trichloroethylene, and vinyl chloride. In northern NJ there were approximately 4600 Known Contaminated Sites (KCSNJ) where these toxins were detected. A total of 269,790 sample detections were identified. Our objective was to identify and map these sites, and identify methods by which more robust contaminant data could be collected and analyzed. This study resulted in eight original maps showing sample detections. These maps will aid researchers and public health advocates in future analyses exploring links between autism and these toxins. Concentrations of multiple toxins associated with ASDs were most dense near urban industrial or mixed residential/industrial areas, though no conclusions can be made regarding association or causality between the sample detections and autism. Based in part on this study, NJDEP has made and will continue to make improvements to contaminant data collection systems. 


\section{Keywords}

\section{ASD, Autism, Contaminant, Neurodevelopmental, Toxin}

\section{Introduction}

The marked rise in reported prevalence rates of autism spectrum disorders (ASDs) is a national public health concern. Estimates from the CDC's Autism and Developmental Disabilities Monitoring (ADDM) Network indicate that approximately 1 in 68 children in the U.S. have been diagnosed with ASDs [1]. New Jersey (NJ) has the highest prevalence rate among states surveyed, with approximately 1 in 45 children diagnosed with ASDs [1]. This estimate for New Jersey was the highest ever reported for a single site in the ADDM Network. With the continued rising rates in diagnosis of ASDs in NJ, concern is mounting regarding environmental factors potentially associated with autism. While a number of toxins have been implicated, more environmental health research is critically needed. Preliminary evidence supports an association between proximity to toxic sites and the prevalence of autism [2], as reported by Eric London and Ruth Etzel. Referencing the Brick Township, NJ "cluster," [3] Palmer et al. demonstrated a connection between environmental mercury release and autism prevalence rates in Texas [4] and DeSoto in Minnesota documented "that within the state with the highest rate of ASDs, the rate is higher for schools near Environmental Protection Agency (EPA) Superfund sites” [5]. Furthermore, Ming et al. in New Jersey examined the relationship between toxic sites and autism diagnoses, concluding, "The area of highest ASDs cases coincides with the highest density of toxic landfill sites while the area with lowest ASDs cases has the lowest density of toxic landfill sites... These significant observations call for further organized studies to elucidate possible role(s) of environmental toxicants contributing to the pathogenesis of ASDs" [2].

The main objective of this study was to identify and map known locations of eight contaminants most associated with autism in the published literature. We collaborated with the NJDEP to gather location data for all Known Contaminated Sites of New Jersey (KCSNJ) from 2005 to 2007 related to the detection of specific environmental factors previously linked to the development of ASDs: arsenic, lead, manganese, mercury, organophosphorus pesticides (OPPs), polychlorinated biphenyls (PCBs), trichloroethylene (TCE), and vinyl chloride. This pilot does not distinguish between samples that were simply detected in the environment and sample results that were above regulatory standards.

\section{Methods}

\subsection{NJDEP Data Mining}

NJDEP reports Known Contaminated Sites in New Jersey (KCSNJ) information in three categories: “Active Sites with Confirmed Contamination", "Pending Sites with Confirmed Contamination”, and "Closed Sites with Remediated Contamination". The reports include all cases and activities at a site, including residential and commercial sites, and EPA Superfund sites. For this study, only data from "Active Sites with Confirmed Contamination" was used during the study period 2005-2007. The process of this data mining uncovered that ours was the first research team to request this data. The process revealed opportunities for improvements to the data collection and content management systems that needed to be addressed for our study and for future environmental health research.

For this study, the Excel and tab-delimited formats of the active site reports include mapping coordinates for most sites. Additionally, the NJDEP website contains a map of New Jersey with links to data layers [6]. Eight contaminants were selected based on published reviews of environmental factors and autism: arsenic, lead, manganese, mercury, OPPs, PCBs, TCE, and vinyl chloride [7] [8]. The study team then requested KCSNJ datasets by contaminant, which were data mined by NJDEP.

\subsection{Data Geo-Processing}

Using best practices, contaminant location data from NJDEP was mapped and reviewed for quality control using ESRI's ArcGIS (version 10) software. A summary of the mapping shows the number of initial records, number of mapped points after excluding media types "Other", "Waste” and "Missing” and field duplicates from the 
NJDEP dataset (see Table 1). All sample results where one or more of the eight contaminants were detected, with available location coordinates and geocoded coordinates were mapped.

NJDEP provided contaminant data in tabular .csv format. All tables were subjected to similar geo-processing operation for quality control. The chemical tables were imported into a geodatabase, and points were mapped from fields displaying coordinate information. Within the tables, three sets of columns contained spatial data: SPX/SPY, PIX/PIY, XCOORD/YCOORD. These fields contained coordinates in North American Datum 1983 (NAD83), New Jersey State Plane feet. The three sets of coordinates handled locations differently and the SPX/SPY fields were found to be the most accurate for the locations of the sample points. In cases where samples did not have SPX/SPY coordinates, point locations were mapped using either of the two remaining sets of location data: PIX/PIY or XCOORD/YCOORD. Samples that did not have location information were omitted from mapping.

The resulting mapped points were reviewed for outliers. In the case of the chemical data, each point had to lie within its corresponding municipality and match the municipal ID. There were instances where the municipal IDs for a sample point fell within an immediately adjacent municipality. In this case it was considered a notation error, and the point was retained for analysis. A point was considered an outlier if it was found mapped outside of its own municipality and beyond an immediately adjacent municipality. Outliers were removed from the dataset.

\subsection{KCSNJ Data Contaminant Criteria}

We requested KCSNJ that were active from 2005-2007, the baseline period of this study. This timeframe was selected to correspond to an age group of patients with ASDs diagnosed at HackensackUMC's Institute for Child Development in order to allow for additional research. The ten northern New Jersey counties included were: Bergen, Morris, Essex, Hudson, Passaic, Sussex, Union, Middlesex, Somerset and Warren.

For the eight contaminants selected, 269,790 points of detection qualified for inclusion in the KCSNJ database during this time frame. Media types included in the study were surface water, groundwater, air, soil, sediment and solid. Specifically, Boolean filters were applied to capture: a) all surface water samples, b) ground water as influent and effluent, c) potable ground water, d) leachate from soil, sediment and ground water. Additionally, samples described as soil, ground water and sediment not flagged by Boolean screening were also included in the study (see Table 2 and Table 3).

Beginning in 1997, the state required that responsible parties at contaminated sites provide results from environmental sampling at remediation sites in a computer-readable electronic format with the coordinate location of every sampling point. Environmental consultants and labs working for the responsible party typically prepare a table of laboratory results and a corresponding table of sample information to make a dataset known as an electronic data deliverable (EDD) for the Site Remediation Program (SRP), which oversees data collection for KCSNJ. The SRP applies automated checking to each EDD it receives, and adds the EDD to the program's HazSite Database. That database is the most easily queried collection of information about individual contaminants that

Table 1. Summary of the ArcGIS mapping.

\begin{tabular}{ccc}
\hline & Characteristic & \\
\hline Table & Initial Records & Mapped Sample Points \\
\hline Arsenic & 104,866 & 48,733 \\
Lead & 91,889 & 86,449 \\
Manganese & 21,766 & 20,150 \\
Mercury & 28,730 & 26,885 \\
OPP & 61 & 54 \\
PCB & 26,600 & 25,215 \\
TCE & 50,516 & 47,314 \\
Vinyl Chloride & 16,148 & 14,990 \\
Subtotal & 340,576 & 269,790 \\
\hline
\end{tabular}


Table 2. Field Interpretation.

\begin{tabular}{|c|c|c|}
\hline $\begin{array}{c}\text { Boolean } \\
\text { Screening Fields }\end{array}$ & True Sample & False Sample \\
\hline isSoil & $\begin{array}{l}\text { sample has MATRIX “soil” or "solid" or another field (SAMPNUM, FIELDID, SAMPTYPE, } \\
\text { SAMPMETHOD, SAMPNOTE) contains a substring like "soil” or "bore" or "boring” or } \\
\text { "geoprobe" or "fill” or "postex" or "pile" }\end{array}$ & \\
\hline isSurfWater & & All as of $08 / 19 / 2011$ \\
\hline isSed & $\begin{array}{l}\text { has MATRIX “sediment" or if the substring "sed" in another field (SAMPNUM, FIELDID, } \\
\text { SAMPTYPE, SAMPMETHOD, SAMPNOTE) or if ANLYS_MTHD indicates simultaneously } \\
\text { extracted metals (SEM) or acid volatile sulfide (AVS) or a substring like "821*91-100" }\end{array}$ & \\
\hline isLeachate & $\begin{array}{l}\text { some field in HZSAMPLE or HZRESULT mentions "leachate" or a method like Extraction } \\
\text { Procedure Toxicity (EP-TOX, SW846 prep method 1310), Toxicity Characteristics Leaching } \\
\text { Procedure (TCLP, SW846 prep method 1311), Synthetic Precipitation Leaching Procedure } \\
\text { (SPLP, SW846 prep method 1312), or another prep method that extracts contaminants with } \\
\text { water. "Leachate" may also refer to the liquid found within the liner of a landfill }\end{array}$ & \\
\hline isGW & 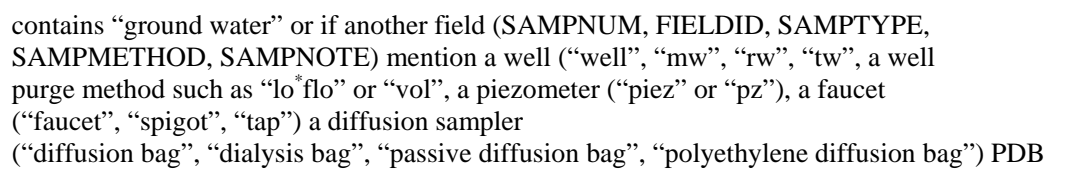 & \\
\hline isPotable & record contains evidence that the water tested is intended to be drinking water & \\
\hline isSGorIAorOA & ANLYS_MTHD mentions method TO-15 or TO-17 NJDEP LLTO-15 & \\
\hline isInfluent & "influent” or if "infl” appears in another field & \\
\hline isEffluent & SAMPTYPE is "effluent" or if "effl" appears in another field & \\
\hline isND & sample is none detected & \\
\hline isMS & $\begin{array}{l}\text { created by the laboratory for quality assurance, such as a matrix spike (MS), a matrix spike } \\
\text { duplicate (MSD), a blank spike (BS), blank spike duplicate (BSD), a lab control } \\
\text { sample (LCS), or a continuing calibration verification sample (CCV) }\end{array}$ & \\
\hline isBlank & $\begin{array}{l}\text { Sample is one created outside the lab to rule out cross contamination. Blanks can include } \\
\text { a field blank (FB), a trip blank (TB), a storage blank, or a rinsate blank (RB) }\end{array}$ & \\
\hline isWaterMeth & ANLYS_MTHD describes a method that is specific to samples of drinking water or other water & \\
\hline isAir & & All as of $08 / 19 / 2011$ \\
\hline
\end{tabular}

Table 3. Results.

\begin{tabular}{|c|c|}
\hline Boolean Classes & Results \\
\hline isSoil & True And all others are false: 191,793 records \\
\hline \multirow{2}{*}{ isSed } & isSed = True And all others are false: 12,326 records \\
\hline & isSoil $=$ True And isSed $=$ True, and all 10 others are false: 1689 records \\
\hline \multirow{4}{*}{ isLeachate } & isSoil $=$ True And isLeachate $=$ True And all others are false: 383 records \\
\hline & isSed $=$ True And isLeachate $=$ True And all others are false: 659 records \\
\hline & isLeachate $=$ True And isGW = True And all others are false: 58 records \\
\hline & isLeachate $=$ True And all others are false: 165 records \\
\hline \multirow{6}{*}{ isGW } & Probably non-potable ground water: \\
\hline & isGW = True And all others are false: 128,963 records \\
\hline & isGW = True And isInfluent = True And all others are false: 641 records \\
\hline & isGW = True And isEffluent = True And all others are false: 244 records (probably treated) \\
\hline & Probably potable ground water: \\
\hline & isGW = True And isPotable = True And all others are false: 892 records \\
\hline isSGorIAorOA & (indicates a sample of Soil Gas or Indoor Air or Outdoor (Ambient) Air) True And all others are false: 2536 records \\
\hline isInfluent $^{*}$ & True And all others are false: 174 records \\
\hline isEffluent ${ }^{*}$ & True And all others are false: 94 records \\
\hline isSurfWater & Results postponed \\
\hline
\end{tabular}

* Records Need Further Review. 
exist or existed at a KCSNJ location.

NJDEP's goal is to have all coordinates conform to New Jersey's State Plane Coordinate System, based on the North American Datum of 1983 (NAD83). However, in some cases, coordinates were found to be from a prior coordinate system, the North American Datum of 1927 (NAD27). For this study, all KCSNJ points were supplied in NAD83. The coordinates in the contaminant tables included some points in NAD27. The KCSNJ list was downloaded from the NJDEP GIS website (where data included latitude and longitude information) and toxins data was provided by the SRP.

Coordinate locations, usually corresponding to the front door of the property, are available from three sources at NJDEP. NJDEP estimates that about 1\% of locations were lacking coordinates. Of these locations or those with conflicting coordinates, many had addresses that were sufficient in identifying coordinates, or for verifying these coordinates with web mapping applications.

\subsection{KCSNJ Data Contaminant Categories}

NJDEP lists each contaminant as "detected” or "non-detected”. Only detected were included in the study. The detection is determined by the laboratory’s reporting limit, also called the "practical quantization limit” (PQL). The reporting limit is distinct from a "method detection limit" (MDL), an optimistically low estimate of the lowest concentration a particular method can detect for a particular chemical compound. The reporting limit should be higher than the MDL. A contaminant appears in the NJDEP database as "non-detect" if it is below the lab’s reporting limit. Detection limits and reporting limits do vary between analytical methods, from analyte to analyte within the same analytical method, and from lab to lab. Therefore, this study's dataset includes all sites where the eight contaminants were detected (any contaminant measurement above zero).

Flags added to records from the HazSite Database indicate the most likely matrix (medium) sampled. (The flag was based on information in the "Matrix" and "SampType" fields and other information provided with the sample.) Table 2 and Table 3 show the data supplied by NJDEP for this research study.

\section{Results}

\section{Eight Contaminant Maps \& KCSNJ Findings}

The primary results from this study are the creation of eight original maps in NJ showing known contaminated sites of toxins previously linked to ASDs. To our knowledge, these are the first published maps of these sample detections. The maps were created by the New Jersey Meadowlands Commission/Meadowlands Environmental Research Institute (NJMC-MERI) using NJDEP data. Each map depicts the points of detection for one contaminant, showing its locations within the ten northern New Jersey (NJ) counties included in this study. Concentrations of multiple contaminants were most dense in northeastern NJ, near urban-industrial or mixed-residential/industrial areas.

Together, the maps show 269,790 points of detection in surface water, groundwater, air, soil, sediment and solid. There were 48,733 for arsenic (see Figure 1); 86,449 for lead (see Figure 2); 20,150 contamination points for manganese (see Figure 3); 26,885 for mercury (see Figure 4); 25,215 for polychlorinated biphenyls (see Figure 5); 47,314 for trichloroethylene (see Figure 6); 14,990 for vinyl chloride (see Figure 7); 54 for organophosphorus pesticides (see Figure 8). It must be noted that much of northern New Jersey contains high "background” levels of arsenic, which is reflected in a generic, state-wide soil standard of $19 \mathrm{mg} / \mathrm{kg}$, above the health-based criterion of $0.5 \mathrm{mg} / \mathrm{kg}$ due to these naturally-occurring concentrations [9].

\section{Discussion}

\subsection{Data Limitations}

As with all data, irregularities exist. NJDEP data is collected by external consultants at individual labs, which may vary in adherence to the agency's sampling manual guidelines. Data for each site is run through an automated checker system at NJDEP for quality control. Each contamination case has a start date and, if it has since been closed, an end date. The start date indicates when the contamination was reported, not when contamination began. The case end date states when activity was completed at a site, which may indicate transfer to another bureau for management purposes, or that a letter of No Further Action (NFA) was issued. For some sites, 


\section{Environmental Contaminants in Northern $\mathrm{NJ}$} Funded by the U.S. Centers for Disease Control and Prevention



Figure 1. Arsenic sample locations. 


\section{Environmental Contaminants in Northern $\mathrm{NJ}$}

Funded by the U.S. Centers for Disease Control and Prevention

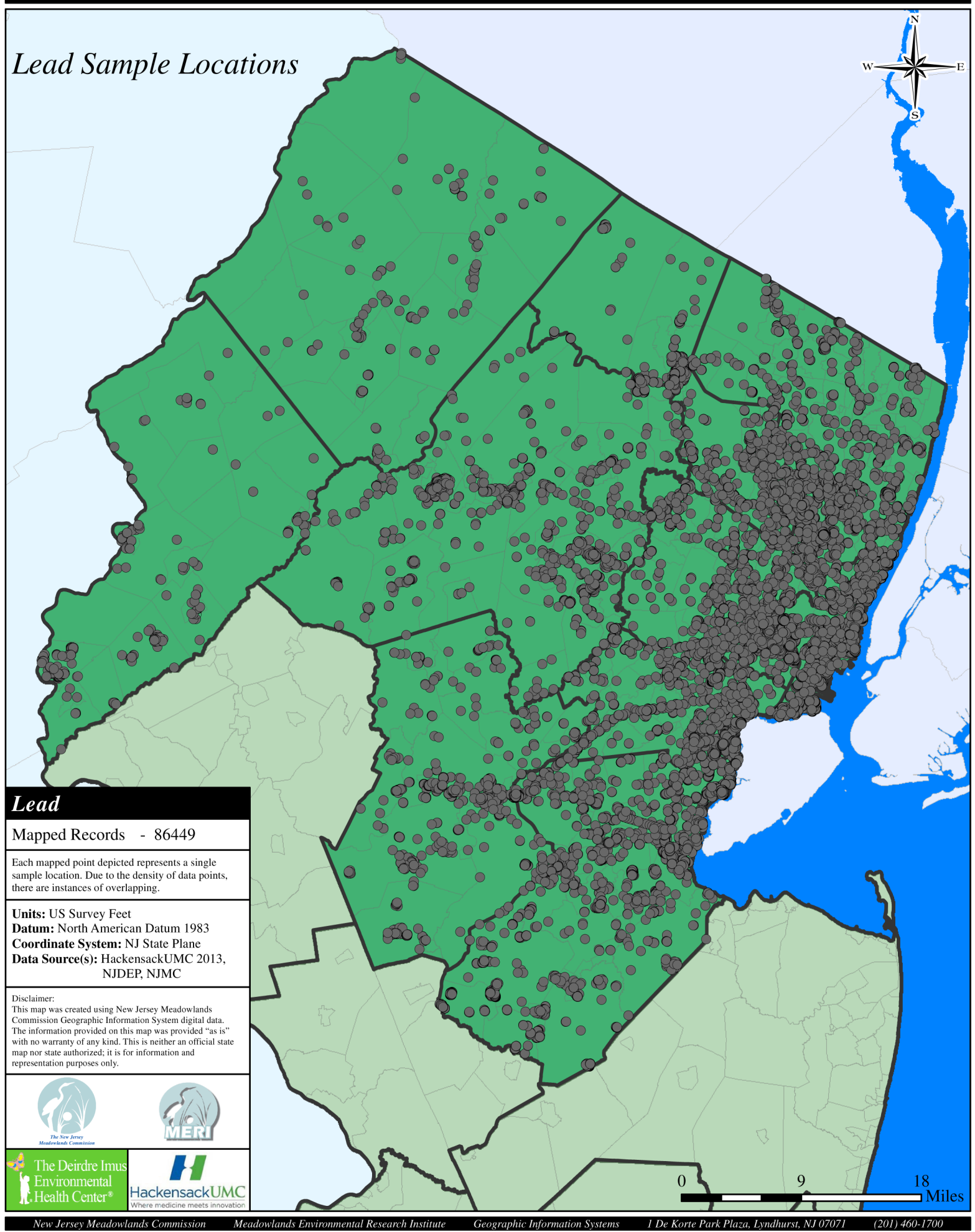

Figure 2. Lead sample locations. 


\section{Environmental Contaminants in Northern NJ Funded by the U.S. Centers for Disease Control and Prevention}

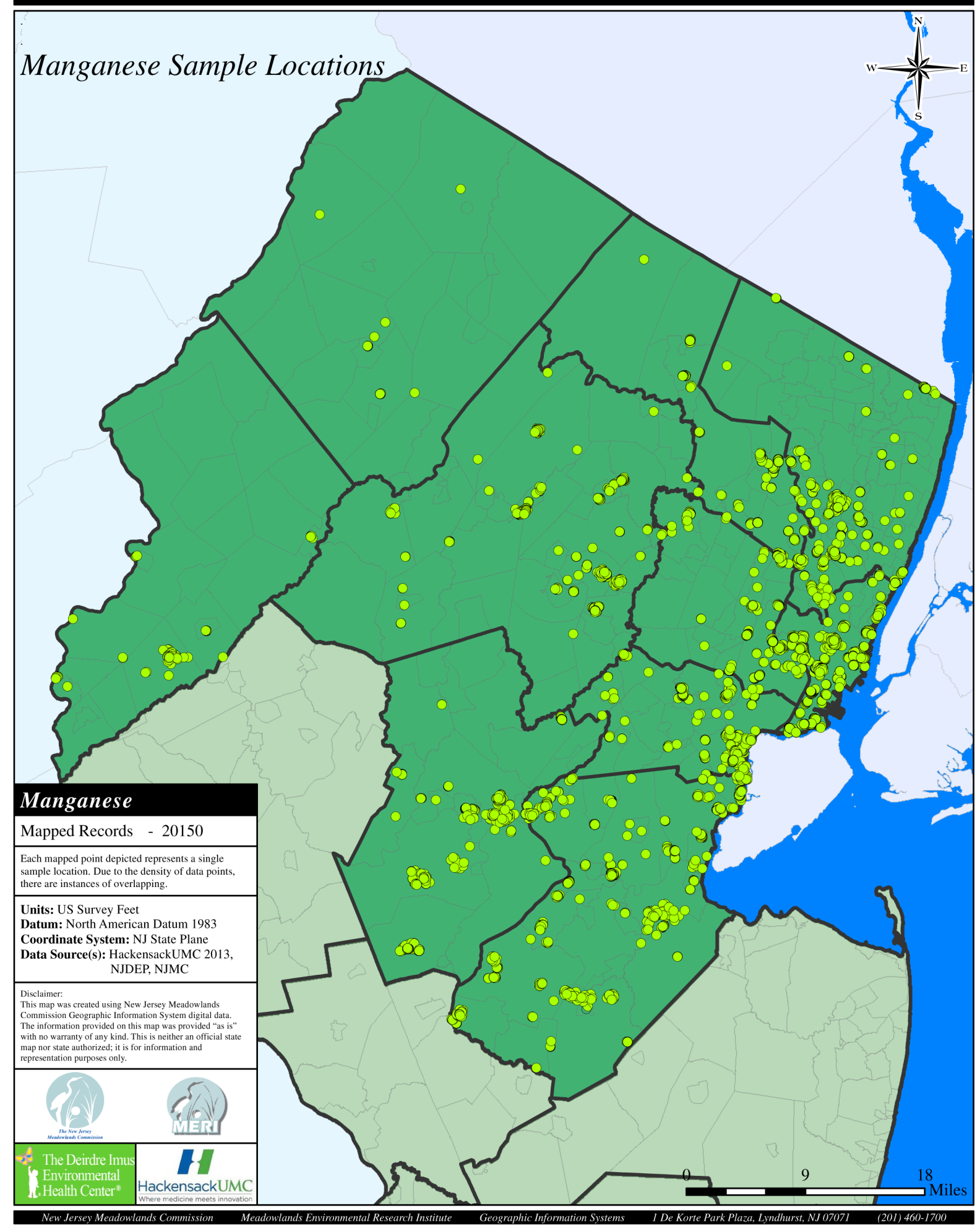

Figure 3. Manganese sample. 


\section{Environmental Contaminants in Northern $\mathrm{NJ}$}

\section{Funded by the U.S. Centers for Disease Control and Prevention}

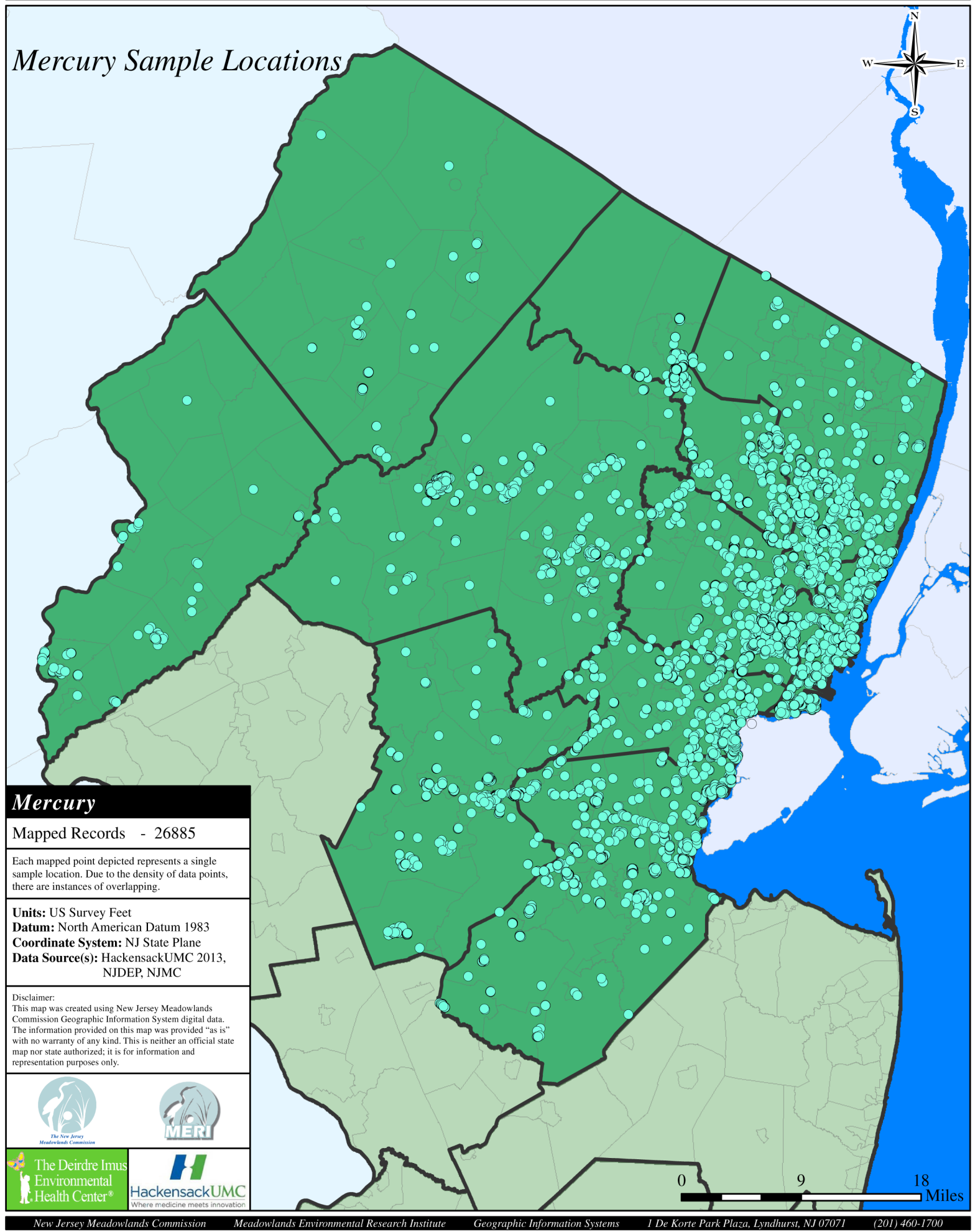

Figure 4. Mercury sample locations. 


\section{Environmental Contaminants in Northern $\mathrm{NJ}$}

Funded by the U.S. Centers for Disease Control and Prevention

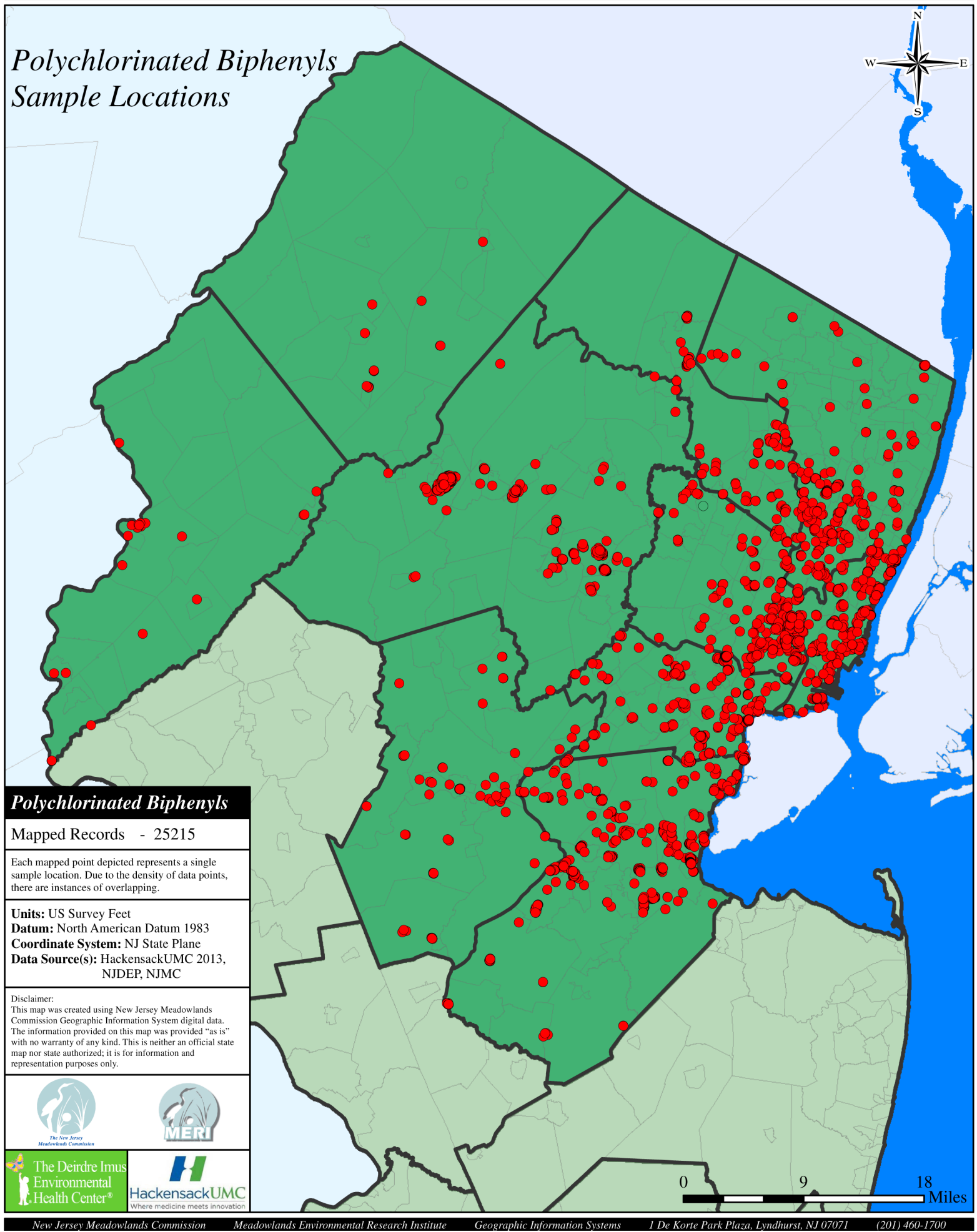

Figure 5. Polychlorinated biphenyls sample locations. 


\section{Environmental Contaminants in Northern NJ}

Funded by the U.S. Centers for Disease Control and Prevention

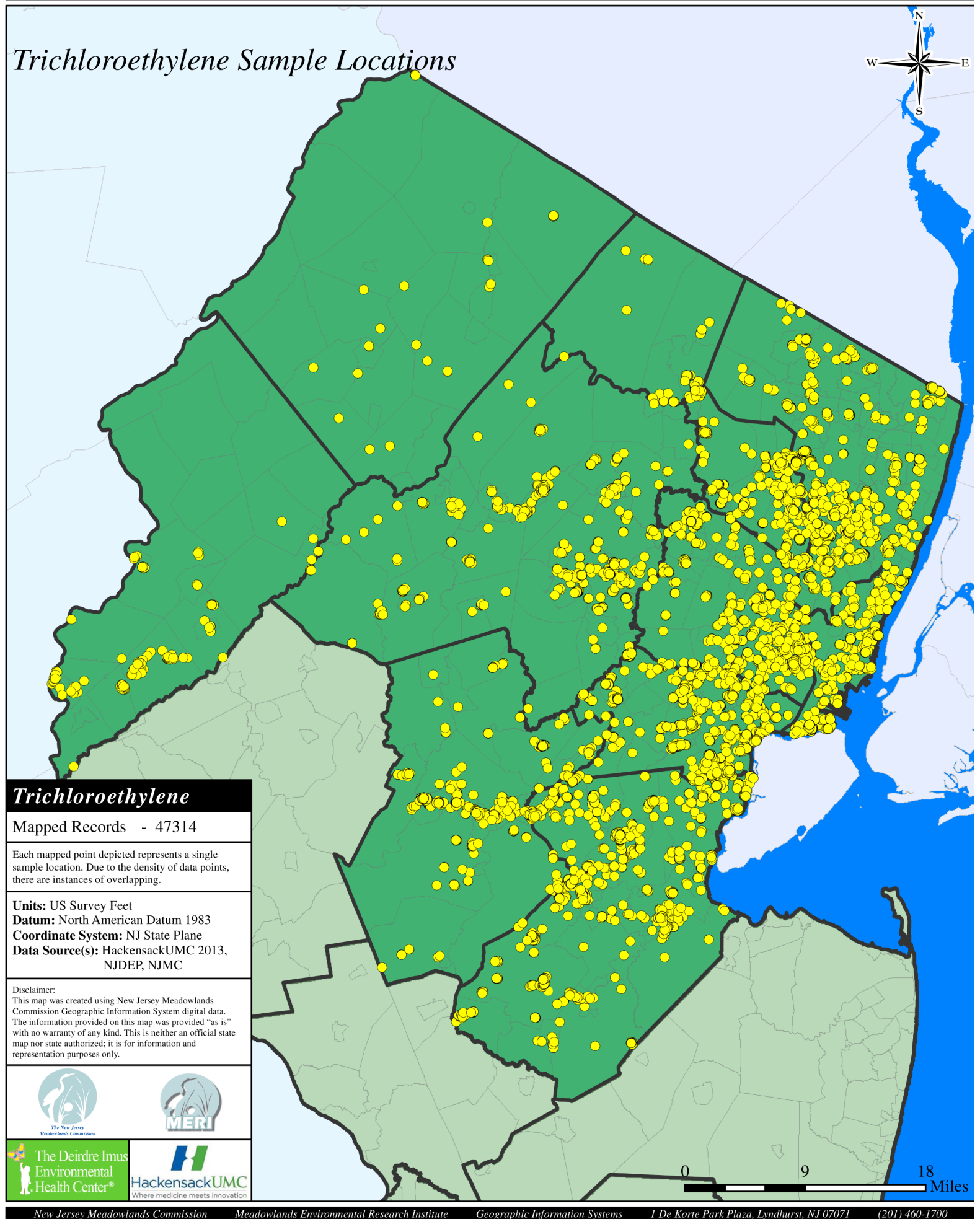

Figure 6. Trichloroethylene sample locations. 


\section{Environmental Contaminants in Northern $\mathrm{NJ}$} Funded by the U.S. Centers for Disease Control and Prevention

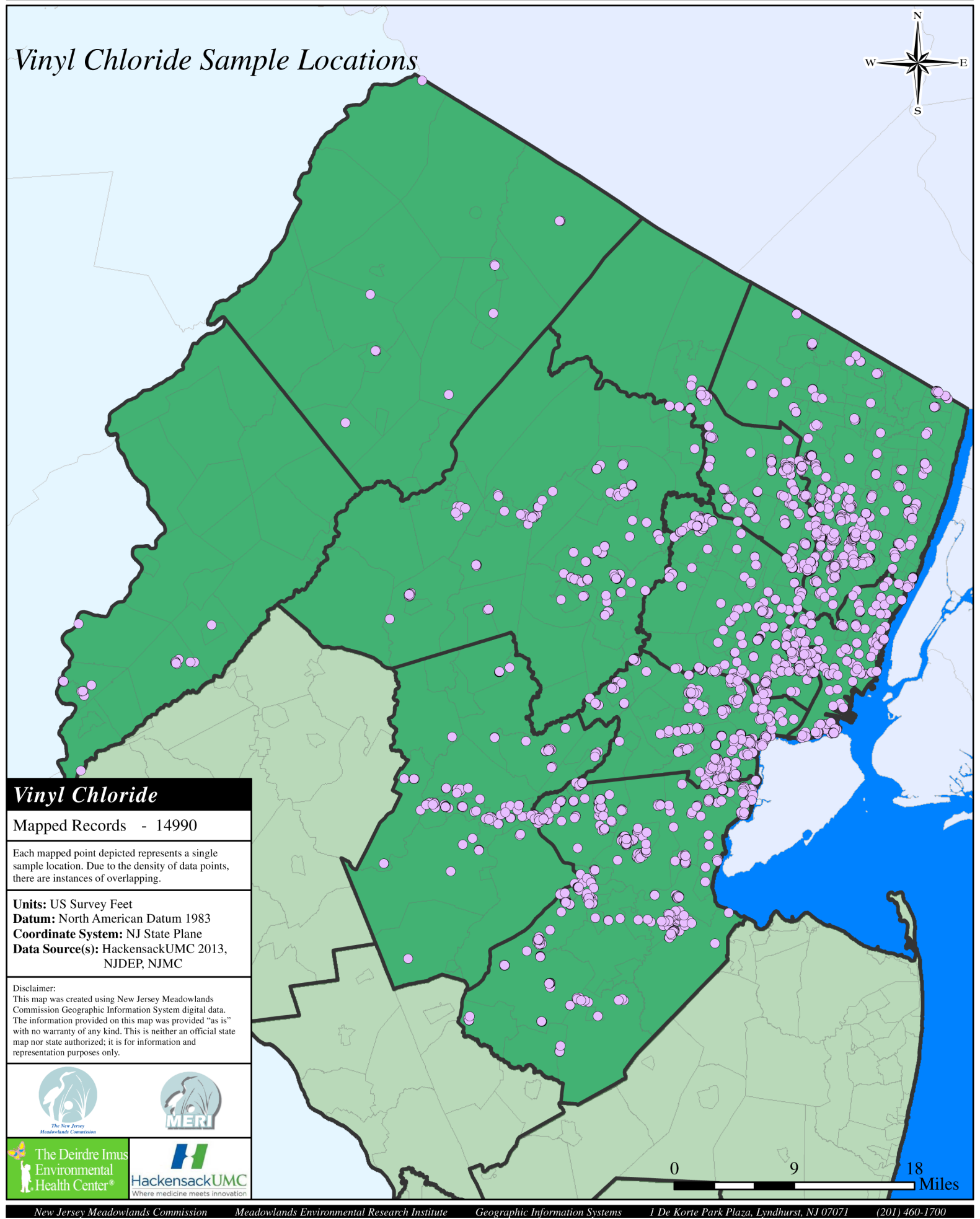

Figure 7. Vinyl Chloride sample locations. 


\section{Environmental Contaminants in Northern NJ}

\section{Funded by the U.S. Centers for Disease Control and Prevention}

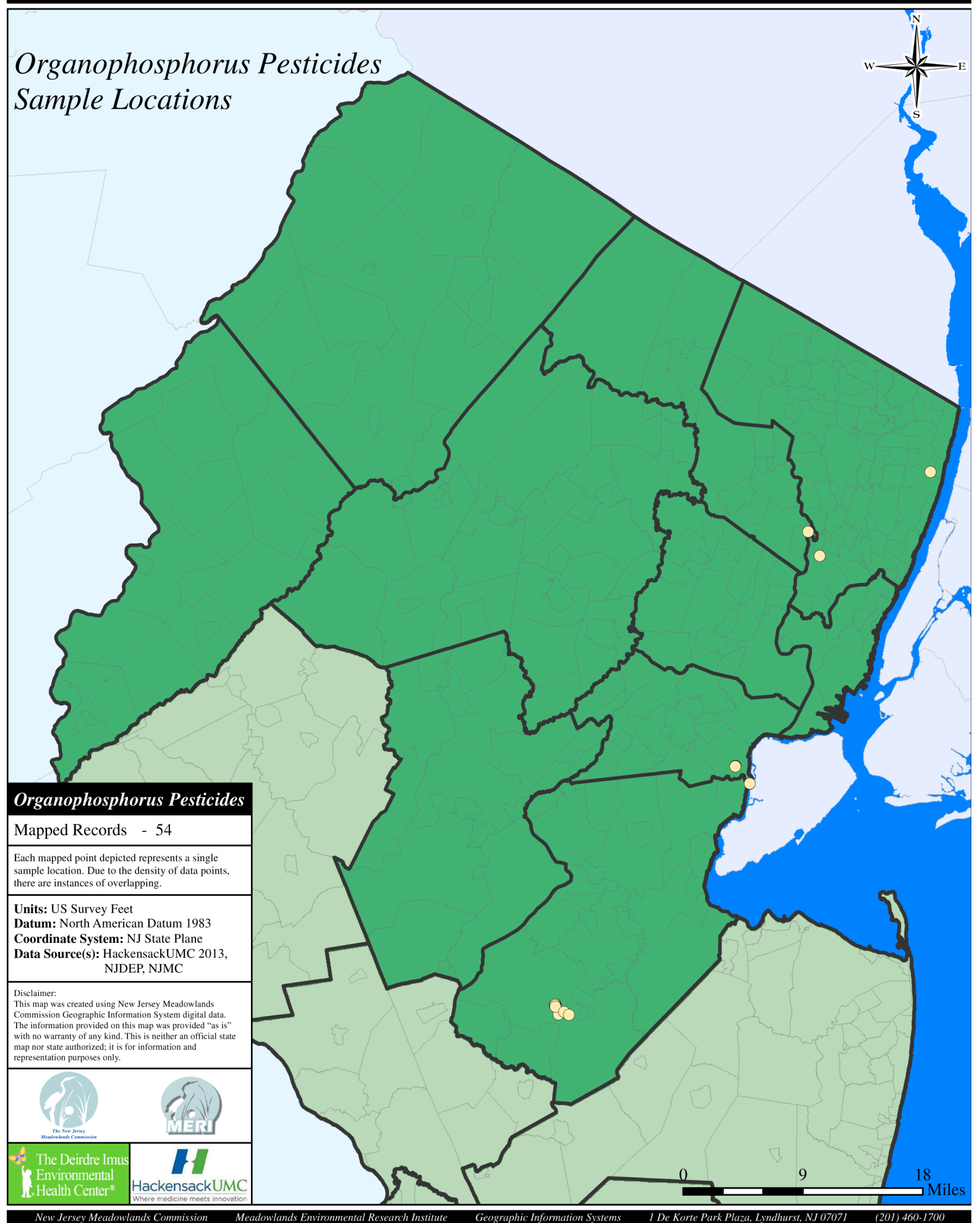

Figure 8. Organophosphorus pesticides sample locations. 
NJDEP may be able to supply a date when all cases at the site were closed.

NJDEP acknowledges that KCSNJ site numbers may have inconsistencies over time, as the agency may need to change it as more information becomes available or a site is reclassified. The primary reason for changes in site identification numbers from list to list is that different programs within NJDEP generate their own numbers to identify sites. For example, the Air Program may identify a contaminated site with a different number than the Site Remediation Program. In 2001, NJDEP began the ongoing effort of consolidating duplicate addresses into one site record. Therefore, for this study, linking data snapshots from every few months to each other and to the full database proved challenging. Any duplicate KCSNJ listings were deleted, as it is possible for one case to be on several lists (e.g. a case listed from April 2005 through October 2007).

Investigations for remediation involve the collection and analysis of samples from several types of media. These classifications are often determined by the person conducting the analysis based on their company's classification system, which typically has categories different from those used by the NJDEP Haz Site Database. For example, stream sediment is sometimes classified as soil, or the lab may indicate "surface water" though the testing site was, in fact, groundwater (such as a monitoring well). When necessary, NJDEP does change classifications. It must be noted that soil may sometimes be sampled at a very deep level, as indicated in the data from NJDEP. This may suggest that public exposure was minimal, though even small exposures may result in significant human health impacts. This study did not evaluate exposure pathways (addressed in NJ Administrative Code 7:26D, Remediation Standards, the methods by which humans can come into contact with contamination including, but not limited to, the ingestion-dermal and inhalation exposure pathway).

Some samples reported in NJDEP Haz Site records were spiked samples for quality control. A laboratory artificially spikes aliquots of selected samples with target contaminants to check the accuracy of the analytical procedure. NJDEP flagged those it could identify to indicate that DIEHC should omit them, but could not guarantee all were flagged. NJDEP searched for results reported in percent units and for sample identifiers containing initials such as "MS" and "MSD” indicating a matrix spike and a matrix spike duplicate, respectively.

Another limitation of the data is that easting and northing in the coordinate location are sometimes reversed. In addition, some EDD preparers did not calculate, from available information, the alternative latitude and longitude coordinates in the required units of degrees, minutes and decimal seconds. Correcting such coordinate errors is a large manual process that has not been completed for all parts of the Haz Site Database. Per NJDEP, although users of the HazSite Database records supplied to DIEHC need to be aware of this, the majority of the records have site coordinate information from two other sources.

Additionally, NJDEP reports a very small percentage of dates with Y2K errors. EDD preparers who entered two-digit years reported dates in the early 1900s that are unambiguous but awkward to process. NJDEP began receiving data in electronic form in July 1997, so the issue did not appear in the earliest years of data collection. Incorrect century dates are mixed with truncated four-digit-year dates that are quite ambiguous when written as 2019 or 2020.

Regarding special circumstances with certain contaminants, PCBs are different from other contaminants as they make up a class that includes 209 distinct compounds known as congeners and several commercial mixtures (Aroclor 1016, Aroclor 1221 and others). Therefore several individual concentrations in a sample may need to be aggregated (summed) to an overall concentration of PCBs. TCE and vinyl chloride both have potential health effects at very low levels that may be difficult to detect.

It must be noted as a study limitation that NJDEP has knowledge of data that were collected and were not yet entered into the HazSite database. One NJDEP estimate is that approximately half of all available KCSNJ data had been entered into the system from summer 1997, when DEP's electronic data collection system debuted, through 2011. Some cases had paper forms instead of electronic data. The requirement to submit electronic data in an acceptable format was not strictly enforced for a period of time, therefore some data gaps resulted.

There remains a need to assess how state and federal data overlap and work as separate systems in order to provide a more comprehensive picture of contamination. Government TOXMap data is extremely useful, but does not contain the same information as NJDEP or other state data, although in NJ some overlap does exist with Superfund site listings [10]. TOXMap contains Toxic Release Inventory (TRI) data and EPA Superfund data, and has its own limitations as with any database.

\subsection{Study Influence on Current and Future Data Collection at NJDEP}

Based in part on the data mining necessary for this research study, NJDEP updated the "guidance" and "checker" 
for the Site Remediation Program electronic deliverable database. This includes a new manual and new rules for what fields (columns) are required, as well as the addition of new fields. These updates began after summer 2011, when the agency commenced obtaining data for this study. NJDEP re-programmed the system's electronic data "checker" to eliminate challenges brought to light through our information request. Specifically, the automated "checker" either approves or does not approve incoming data received by NJDEP. If data is not approved, it may contain information that NJDEP asked the responsible party to clarify or provide, such as coordinates. If the responsible party does not comply, this becomes unapproved data. Approved data means the system found no error messages. When data is unapproved and then fixed, the approved data replaces the unapproved information in the system.

With the new checker system, the consultant receives the data back from the lab and forwards it to NJDEP via both electronic and written form. The written form is included in the report. In 1997, NJDEP began requiring data to be supplied electronically. Since fall 2012, more data has been collected, and the review process has been consolidated within one NJDEP bureau, resulting in increased compliance with the data requirements. Previously, several bureaus in the Site Remediation Program (SRP) collected data, which created inconsistencies among case managers regarding inputting and checking for required data.

At NJDEP, the establishment of the new guidance and checker is transforming the accuracy and breadth of data collected. For example, well permit numbers are now required for submitting groundwater samples. Each well now has a fixed identifier, and NJDEP will be able to supply future researchers with all data tied to each well. The changes to the guidance and checker are reflected in the publicly available February 2013 document from NJDEP's Bureau of Information Systems: Site Remediation Program Electronic Data Interchange Manual [11]. The manual includes a sub-section titled HazSite Tables and Fields for the Electronic Data Submittal Application-Version 7 (EDSA7), which contains upgrades particularly influenced by this CDC study [12].

\subsection{Future Research}

Future researchers may consider consulting regulatory agencies such as NJDEP during study design, so that all parties are aware of available data, collection methodology, and limitations. NJDEP has indicated that due to resource constraints and the magnitude of this pilot study, future research must be designed to include data available through NJDEP's Data Miner, GIS downloads and other existing electronic services readily available to the general public. Another future consideration is the degree to which citizens may be exposed to KCSNJ. Important measures of human exposure to consider for future research may be indoor air and well water. For example, there is a risk of human exposure to groundwater via private wells, public supply wells, and wells used by public access areas such as convenience stores or housing developments, all of which are state regulated.

In considering air exposures for future research, NJDEP regulates vapor intrusion into indoor air with increasing frequency. For example, a plume of contamination from a gas station can allow volatile contaminants to escape into groundwater, which can migrate to public access points such as homes and childcare centers. Future research may also consider mixtures of contaminants, such as TCE existing in combination with perchlorethylene (PERC). It is not often that contamination is comprised solely of one contaminant.

Future work may also consider that the EPA is the lead investigator for some KCSNJ located on federal Superfund sites, and may have additional data, though not in the same format as NJDEP. Not all states require data in electronic format and currently, there are no concrete plans to link different states' records. This is an area where greater oversight and state-to-state collaboration are greatly needed for the advancement of public health.

\subsection{Considerations for Autism and Public Health}

Autism remains an urgent public health concern, and a major research priority is elucidation of risk factors and causes for this complex neurodevelopmental disorder. The social, medical and economic costs of ASDs to families are tremendous: the cost to society is estimated at $\$ 35$ billion to $\$ 90$ billion annually [8]. As children with ASDs become adults, there is an increased need for medical, housing and other support services.

The impact of findings from research on ASDs and environmental factors is critical to public health. For example, how should doctors advise families, pregnant women and those considering conception currently living near contaminated sites? How should public health officials be advised as to health risks to the general public? What legislative policies should be enacted to protect families? Can we measure toxicity reliably in children with ASDs? If so, can we safely and effectively reduce this toxic burden and would such treatments ultimately 
result in sustained improvement in neurocognitive functioning? Why do environmental factors appear to affect some children more than others? Accordingly, the 2011 Interagency Autism Coordinating Committee Strategic Plan for Autism Spectrum Disorder Research pointed out the need for research that delineates which environmental factors are associated with the development of autism in vulnerable populations.

Translation of our research findings to real-world end-users will help promote public health by further elucidating the role of the environment in ASDs causation and the need for ongoing environmental toxin surveillance. Public health policies must also address these areas of need.

Partnership in this research project was key not only to the completion of the study but also to its ultimate value. The collaboration among team members is a model of transdisciplinary clinical research, critical to the study of a complex, multi-determined condition like autism. We brought together members of the Institute for Child Development, a leading center in New Jersey for the diagnosis of ASDs; The Deirdre Imus Environmental Health Center, a leading research and advocacy center for children's environmental health; the David and Alice Jurist Institute for Research, with experts in study design and analysis, biostatistics, and epidemiology; and environmental science and GIS mapping experts from NJMC-MERI and statisticians from New Jersey Institute of Technology.

Our findings point to specific areas of need for further research to evaluate environmental factors potentially linked to New Jersey's high rate of autism. Further study is necessary to examine the relationship between these environmental factors and the residential proximity of children diagnosed with autism.

\section{Conclusions}

The primary results from this study are the creation of eight original New Jersey maps showing known contaminated sites of toxins linked to ASDs. Together, the maps represent 269,790 points of detection in surface water, groundwater, air, soil, sediment and solid for manganese, vinyl chloride, arsenic, lead, polychlorinated biphenyl, organophosphorus pesticides, trichloroethylene, and mercury. Concentrations of multiple toxins associated with autism spectrum disorders were most dense near urban industrial or mixed residential/industrial areas, though no conclusions can be made regarding association or causality.

KCSNJ data collection and reporting by the NJDEP have been in need of significant enhancements to make information more uniform, robust and accessible. This study has already influenced upgrades in data collection methodology at NJDEP, including establishment of a new guidance and checker, which are making a difference in the accuracy and breadth of data collected. NJDEP continues to upgrade requirements for electronic data deliverables, a process influenced by collaboration with the DIEHC on this research. Improvements to both toxin database collection and management will aid future researchers in better understanding the relationship between environmental toxins and the rising prevalence rates of autism spectrum disorders.

\section{Competing Interests}

The authors declare that they have no competing interests.

\section{Authors' Contributions}

EI participated in the design of the study, study oversight \& drafted the manuscript. TN, AK, and JML performed the statistical analysis and drafted the statistical portions of the manuscript..FA participated in the study design, coordination of the MERI team and contributed scientific expertise. $\mathrm{CH}$ participated in study design and manuscript review process and contributed scientific expertise. DE and SK performed the GIS mapping and created the maps. JYS contributed chemical expertise and review of the manuscript, LR participated in the design of the study, contributed medical expertise and manuscript preparation and detailed manuscript review. All authors read and approved the final manuscript.

\section{Acknowledgements}

This study was funded by the U.S. Centers for Disease Control and Prevention under the title: Environmental Factors of Autism and Neurodevelopmental Disorders in NJ. The research team at The Deirdre Imus Environmental Health Center (DIEHC) would like to thank the following for their expertise and dedication: Randye Huron, MD and Deborah Malone Sieger, M., Ed., LDT/C, Institute for Child Development/HackensackUMC; 
Roger Page, Site Remediation Program/NJDEP; Maxine Maxwell and Rose Williams, Data Coordinators/ HackensackUMC; Nikita Manavi, Intern/DIEHC; the Meadowlands Environmental Research Institute at NJ Meadowlands Commission and statisticians of NJ Institute of Technology.

\section{References}

[1] Centers for Disease Control and Prevention (2010) Prevalence of Autism Spectrum Disorders Among Children Age 8 Years-Autism and Developmental Disabilities Monitoring Network, 11 Sites. MMWR, 63(SS02), 1-21. http://www.cdc.gov/mmwr/preview/mmwrhtml/ss6302a1.htm

[2] Ming, X., Brimacombe, M., Malek, J.H., Jani, N. and Wagner, G.C. (2008) Autism Spectrum Disorders and Identified Toxic Landfills: Co-Occurrence across States. Environmental Health Insights, 2, 55-59.

[3] London, E.A. (2000) The Environment as an Etiologic Factor in Autism: A New Direction for Research. Environmental Health Perspectives, 108, 401-404.

[4] Palmer, R.F., Blanchard, S. and Wood, R. (2009) Proximity to Point Sources of Environmental Mercury Release as a Predictor of Autism Prevalence. Health Place, 15, 18-24. http://dx.doi.org/10.1016/j.healthplace.2008.02.001

[5] DeSoto, M.C. (2009) Ockham’s Razor and Autism: The Case for Developmental Neurotoxins Contributing to a Disease of Neurodevelopment. NeuroToxicology, 30, 331-337. http://dx.doi.org/10.1016/j.neuro.2009.03.003

[6] NJ Department of Environmental Protection (2013) i-MapNJ. http://njgin.state.nj.us/dep/DEP_iMapNJDEP/viewer.htm

[7] Gilbert, S.G. (2008) Scientific Consensus Statement on Environmental Agents Associated with Neurodevelopmental Disorders. Collaborative on Health and the Environment's Learning and Developmental Disabilities Initiative. http://www.healthyenvironmentforkids.ca/sites/healthyenvironmentforkids.ca/files/cpche-resources/LDDIStatement_E A_NeuroDev_Disorders.pdf

[8] Ganz, M.L. (2007) The Lifetime Distribution of the Incremental Societal Costs of Autism. Archives of Pediatric Adolescent Medicine, 161, 343-349. http://dx.doi.org/10.1001/archpedi.161.4.343

[9] NJ Department of Environmental Protection (2007) Site Remediation and Waste Management Program—Remediation Standards; Technical Requirements for Site Remediation. DEP Docket Number: 07-07-04/46 http://www.nj.gov/dep/rules/proposals/050707a.pdf

[10] National Institute of Health/U.S. National Library of Medicine (2013) TOXMAP Environmental Health E-Maps. http://www.toxmap.nlm.nih.gov/toxmap/combo/navigate.do

[11] NJ Department of Environmental Protection (2013) Site Remediation Program Electronic Data Interchange Manual. http://www.nj.gov/dep/srp/hazsite/docs/edi/index.htm

[12] NJ Department of Environmental Protection (2013) HazSite Tables and Fields for the Electronic Data Submittal Application-Version 7 (EDSA7). http://www.nj.gov/dep/srp/hazsite/docs/errorcode/index.html

\section{Abbreviations}

ADDM: Autism and Developmental Disabilities Monitoring; ASDs: autism spectrum disorders; DIEHC: Deirdre Imus Environmental Health Center; EDD: Electronic Data Deliverable; EPA: Environmental Protection Agency; GIS: Geographic Information Systems; HackensackUMC: Hackensack University Medical Center; KCSNJ: Known Contaminated Sites of New Jersey; MDL: Method Detection Limit; MS: matrix spike; MSD: matrix spike duplicate; NAD83: North American Datum 1983; NFA: No Further Action; NJDEP: New Jersey Department of Environmental Protection; NJIT: New Jersey Institute of Technology; NJMC-MERI: New Jersey Meadowlands Commission, Meadowlands Environmental Research Institute; OPPs: organophosphate pesticides; PCBs: polychlorinated biphenyls; PQL: Practical Quantization Limit; SRP: Site Remediation Program; TCE: trichloroethylene; TRI: Toxic Release Inventory. 
Scientific Research Publishing (SCIRP) is one of the largest Open Access journal publishers. It is currently publishing more than 200 open access, online, peer-reviewed journals covering a wide range of academic disciplines. SCIRP serves the worldwide academic communities and contributes to the progress and application of science with its publication.

Other selected journals from SCIRP are listed as below. Submit your manuscript to us via either submit@scirp.org or Online Submission Portal.
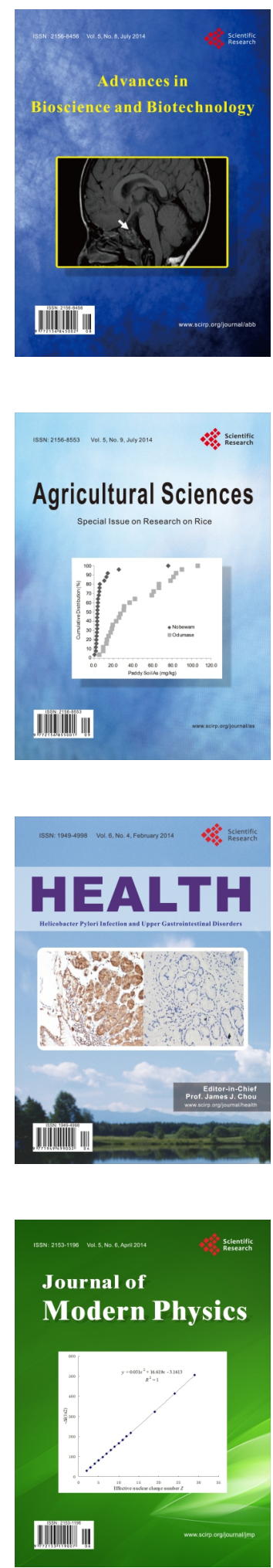
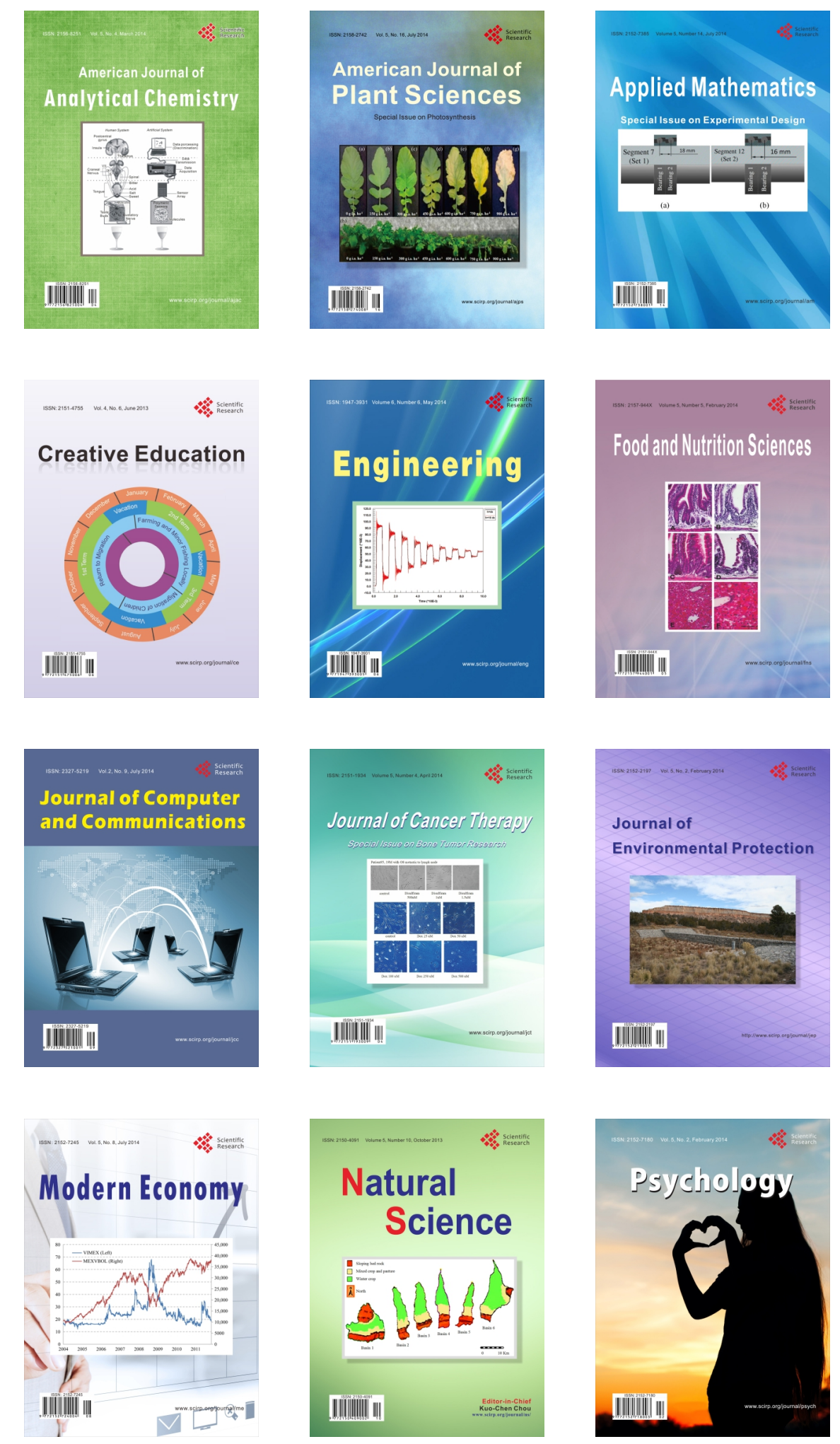